\title{
Survey highlights racialism at top US technology institute
}

Boston

MinORITy students cannot turn to their professors for help because many faculty members expect such students to fail and have little confidence in their abilities. Racial prejudice among the student body adds further to the minorities' difficulties. These startling results emerge from a study conducted by the Massachusetts Institute of Technology (MIT) on its own students and published by the institute.

The study has disturbed the authorities at MIT; it shows that they have failed to create a racially open environment and that the incidence of bias is unacceptably

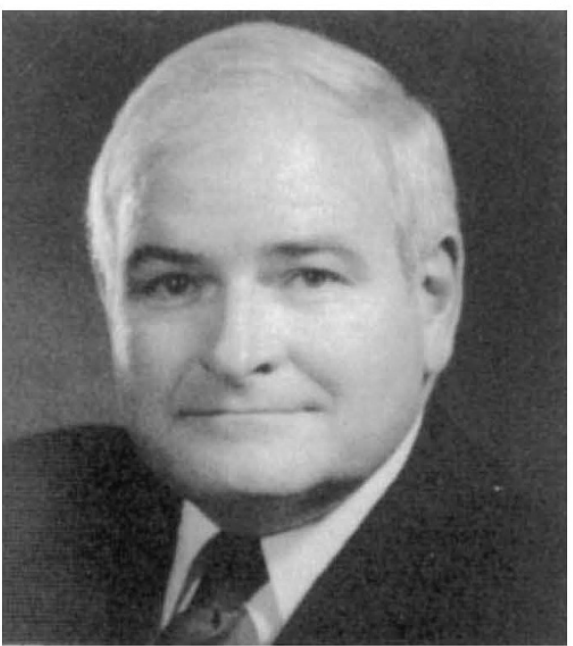

Dr Paul Gray - willing to tackle discrimination.

high. By publishing, says President Paul Gray, the institute shows its willingness to tackle discrimination against minorities and draws attention to the problems facing predominantly white campuses.

The most disturbing behaviour, according to Gray, is the supposed reaction of faculty members to minority students. Over half the respondents to a telephone survey of black MIT graduates reported negative reactions from their faculty members. One third claimed that the staff expected failure or poor ability from them.

Many students quoted in the report echoed the same sentiment. "I went to talk to [a professor] about a grade, and he said that 'maybe you people should go somewhere and do things you people can do"'. Minority students, concludes the report, soon learned not to turn to white faculty members for help. The prejudicial atmosphere is made worse by a much expressed view that high admission standards have been waived for ethnic minorities who otherwise could not have qualified for the institute.

MIT is rigorous for any student, says Gray, and although discrimination compounds the problems for minorities, it is impossible to create a structure formally to eradicate prejudice.

Because 40 per cent of good interactions between faculty and black students was reported to have occurred with the $1-$ 2 per cent of the faculty members who are black, an increase in black faculty could be beneficial. But, says Gray, the number of blacks in science and engineering graduate school is down; the pool of blacks at the doctoral level in relevant disciplines has not increased in 20 years.

The report says that MIT's goal is an interaction between races defined as "pluralism": "Pluralism is different from . diversity, in which individuals from various groups are merely present, just as it differs from the idea of integration, in which minority individuals are asked, ex-

plicitly and implicitly, to abandon their cultural identity in order to merge into the majority community."

How to foster pluralism rather than pressure to segregate or integrate is an open question among MIT students. On an opinion sheet put up for student response, many white students objected to separate living patterns of blacks, while blacks pointed to a need to feel at home somewhere.

An increased applicant pool will help the institute reach a critical mass of minority students, says Gray, but the seesaw in numbers will create an additional problem. Standardized tests, he says, are poor indicators of individual performance but have "substantial meaning" as a group predicator. For a number of reasons, blacks and hispanics score below whites, as Asians score above. Schools "with the expectations of MIT will be in a pickle unless these students come better prepared".

Elizabeth Collins

\section{Hungarian investment needed in research and development}

\section{London}

HuNGARY needs increased investment in research and development, according to the Central Committee of the Hungarian Socialist Workers' Party. A position paper prepared by Dr Lenart Pal, formerly chief secretary of the Hungarian Academy of Sciences and now a secretary of the Central Committee, was "discussed and approved" by the Central Committee on 28 December; it notes that in recent years, party and government decisions urging technical development have not been sufficiently implemented because of a lack of resources and the failure of economic management to make efficient use of such resources as are available. Research and development expenditure should increase, it was urged, more rapidly than national income.

Research and development financing in Hungary involves a range of economic strategies from research con 1 racts between production enterprises and academic research institutes on a strict commercial basis to government support administered through the Central Fund for Technical Development. A feature of Hungarian research and development unique in the socialist bloc is the existence of profitorientated research companies that can apply for government support.

On the basis of the position paper, the Central Committee considered that the profit motive should be further stimulated, with research encouraged by the "differentiated use of finances", an improved scheme of tenders and commission and the creation of competition. Producing and trading companies should "play a determining role in setting the targets of applied research, and the evaluation, application and financing of achievements". At the same time, the scheme by which manufacturing companies now have to contribute 15 per cent of their profits to a centralized technical development fund should be abolished, and each company should be left free to decide how much of its profits to plough back into research and development.

The Central Committee also recommended the "lasting division of labour and cooperation" between the research sector (including the universities) and the production sector, to promote the rapid implementation of scientific achievements in practice. In spite of the cutbacks in the university and academy budgets over the past few years, in at least one field officially considered of paramount economic importance - biotechnology - the trend has gone the other way, and there has been a separation of the academic and applied sectors. Thus, the Szeged Biological Research Centre of the Hungarian Academy of Sciences has cloned off a new commercial biotechnological research centre now under construction on an adjacent site, while government plans announced in 1984 to develop the Agricultural University of Godollo as a major centre for agriculture-related biotechnology were found to be administratively impractical, and materialized instead into a research centre (also now under construction) close to but independent from the university, and the introduction of new, biotechnology-related undergraduate courses in the university itself. Vera Rich 